\title{
DYNAMICS OF A POPULATION SUBJECT TO IMPULSE TYPE RANDOM LOSS
}

\author{
Jevgeniijs Carkovs and Kārlis Šadurskis ${ }^{\#}$ \\ Department of Theory of Probability and Mathematical Statistics, Riga Technical University, 1 Kaḷu Str., Riga LV-1658, LATVIA \\ \# Corresponding author, karlis.sadurskis@rtu.lv
}

Communicated by Jurijs Merkurjevs

\begin{abstract}
We present a qualitative population growth analysis approach using the Pearl logistic population growth differential equation for a population with the intensity of birth a, stationary size $\mathrm{K}$ to instances of fast small random population size extractions proportional to $\varepsilon \xi_{n}$ at random time moments $\tau_{n}$, where $\varepsilon$ is the small positive parameter. Assuming that the intervals $\tau_{n}-\tau_{n-1}$ are independent identically exponentially distributed random variables with the parameter $\lambda / \varepsilon$, and that $\xi_{n}$ are the independent identically distributed positive random variables with the mean $\mathrm{h}$ and the variance $\mathrm{b}^{2}$, we analyse the population dynamics and the population asymptotic behaviour. We propose a probabilistic limit theorem based stochastic approximation algorithm for the qualitative analysis of the above model on any finite time interval. At first we derive the linear differential equation for mathematical expectation $\mathbb{E}\{x(t)\}$ of the population growth and the stochastic lto differential equation for the normalised deviations $(\mathbb{E}\{\mathrm{x}(\mathrm{t})\}-\mathrm{x}(\mathrm{t})) \varepsilon^{-1 / 2}$. Assuming that the difference $\mathrm{a}-\lambda \mathrm{h}=\varepsilon \mathrm{c}$ is sufficiently small we derive the stochastic differential equation for the scaled population growth in accelerated time $\varepsilon^{-1} K x(t / \varepsilon)$ and prove that under condition $2 \mathrm{c}<\lambda\left(\mathrm{h}^{2}+\mathrm{b}^{2}\right)$ the population disappears with probability one, otherwise the distribution of the scaled population size with increasing time tends to the Gamma-distribution $\Gamma(\mathrm{k}, \mathrm{q})$ with the shape $\mathrm{k}=2 \mathrm{c} / \lambda\left(\mathrm{h}^{2}+\mathrm{b}^{2}\right)$ and the scale $\theta=\lambda\left(\mathrm{h}^{2}+\mathrm{b}^{2}\right) / 2 \mathrm{c}$.
\end{abstract}

Key words: population dynamics, stochastic equations, diffusion approximation.

\section{INTRODUCTION: THE MODEL AND ASSUMPTIONS}

The logistic growth model is the most popular one in population dynamics, and considers the birth and death rates typical to the species as well as the effects of different mechanisms of consumption of resources on the dynamics of the biological system. For qualitative analysis of the behaviour of an ecosystem the ordinary differential equation (Otto and Day, 1995):

$\frac{d x}{d t}=\operatorname{ax}\left(1-\frac{1}{K} x\right)-h x$

is commonly used, where the parameter $a$ describes growth rate, i.e. fertility, and the parameter $h$ determines the intensity of extraction of specimens from ecosystem (as an example, the intensity of fishing in the case of fish populations in fisheries, which we use here, and further as an illustrative example scenario). Parameter $K$ corresponds to stationary population size in the case of an absence of fishing, i.e., stationary solution of the equation (1) if $h=0$. As $K^{-1}$ describes the rate of reduction of the population size, this coefficient may be considered as the death rate of the population. Let us note that the stationary solution of the equation (1) $x_{s t}=K\left(1-\frac{h}{a}\right)$

differs from $K$, and solutions of (1) tend exponentially to $x_{s t}$ only if $a>h$. If this inequality is not true, the solution of (1) tends exponentially to zero. This means that the population dies out under such a fishing regime. If the fishing rate $h$ is equal to the birth rate $a$, solutions of (1) also tend to zero, albeit not with an exponential velocity. This means that in order for fishing to be sustainable, it is necessary for the birth rate $a$ to be greater than the fishing rate $h$. It should be noted that it is not just the size of the population that determines the fishing regime. Using the finite difference method, we see that the amount of fishing at time $t$ should be approximately equal to $h x(t) \Delta t$. However, it may be the case that the entire volume of the population $x(t)$ may not be suitable for fishing at the time $t$, and we can only rely on the average value of fishing $h x(t) \Delta t$. Sometimes it is possible to use a different fishing strategy: wait for a time period $\delta$, which, generally speaking, is a random time dependent variable, and only then remove the necessary amount of the population. Therefore, deterministic fishery strategies do not allow us to predict the dynamics of the population size and/or to determine fishing mode, especially if $a \approx h$. In this case, construction and exploration of mathematical models 
of ecosystems by using modern methods of stochastic analysis, as is done, for example, in Prajneshu (1980) and Feldman and Roughgarden (1975) seems to be more productive. Here we also use such a stochastic approach for qualitative analysis of the growth of a population, which in the absence of fishing is subject to the logistic equation (1) with $h=0$. We assume that the parameter that describes the presence of intraspecific competition is sufficiently small and we introduce a small positive parameter $\varepsilon>0$, which will be used as a small parameter for the stochastic approximation of analysing the dynamical system. Therefore, we assume that:

- in the absence of fishing, the population growth is described by the logistic equation

$$
\frac{d x_{\varepsilon}}{d t}=a x_{\varepsilon}\left(1-\frac{1}{K} x_{\varepsilon}\right)
$$

with a parameter of birth rate $a$;

- only individuals who have reached a certain level of maturity are suitable for fishing, and fishing occurs at random time moments $\left\{\tau_{k}, k \in \mathbf{N}\right\}$ and time intervals $\left\{\tau_{k}-\tau_{k-1}, k \in \mathbf{N}\right\}$ are small, mutually independent and exponentially distributed:

$$
P\left(\tau_{k}-\tau_{k-1}>t\right)=e^{-\lambda \varepsilon^{-1 t}}
$$

- volumes suitable for fishing $\varepsilon \xi_{k} x_{\varepsilon}\left(\tau_{k-1}\right)$ at time moments $\tau_{k}$ also are also random, their removal from the population is instantaneous, and therefore at these time moments the trajectory $x_{\varepsilon}(t)$ is discontinuous:

$$
x_{\varepsilon}\left(\tau_{k}\right)-x_{\varepsilon}\left(\tau_{k-1}\right)=-\varepsilon \xi_{k} x_{\varepsilon}\left(\tau_{k-1}\right)
$$

where $\xi_{k}$ are independent identically distributed positive random variables with expectation $\mathbb{E}_{\xi_{k}}=h$ and variance $\mathbb{D} \xi_{k}=h$. As further on we shall take a limit if $\varepsilon \rightarrow 0$, here we use a sub-index $\varepsilon>0$ for analysing the stochastic process by the previously introduced parameter $\varepsilon$.

In the above formulas $x_{\varepsilon}\left(\tau_{k}-\right)$ means the left hand side limit. Let us note that the assumption of exponential distribution of time between any two discontinuities of the trajectories suggests that the probability characteristics of the dynamic system at any fixed time moment $t$ is completely determined by its present value at the time $t$ and does not depend on previous states of the model, i.e. guarantees Markov property of these random processes. This makes it possible to advance the method proposed in Anisimov (1995) and Korolyuk and Limnios (2005) of the diffusion approximation for switching Markov processes and construct a stochastic approximation procedure for impulse type differential equations with fast Markov impulse switching (2)-(4). The resulting differential equation for the mean value of population size and stochastic differential equations for deviations on the mean permit us to describe the probability characteristics of population dynamics.

\section{AVERAGING AND NORMALISED DEVIATIONS}

$\left\{x_{\varepsilon}(t), t \geq 0\right\}$ defined by equations (2)-(3)-(4) can be proved to satisfy the Markov property (Dynkin, 1965). For any bounded continuous function $\{v(x), x \in \mathbb{R}$ and any $t>0$, $\Delta>0$, the conditional expectation of $v\left(x_{\varepsilon}(t+\Delta)\right)$, provided that the part of trajectory $\left\{x_{\varepsilon}(s), 0 \geq s \geq t\right\}$ is known, depends only on $\left\{x_{\varepsilon}(t), t \geq 0\right\}$ :

$$
\mathbb{E}\left\{v(x \varepsilon(t+\Delta)) \mid x \varepsilon(s), 0 \leq s \leq t=\mathbb{E}\left\{v\left(x_{\varepsilon}(t+\Delta)\right) / x_{\varepsilon}(t)\right\}\right.
$$

This permits (Dynkin, 1965) to analyse the probabilistic properties of any trajectory $\left\{x_{\varepsilon}(t), t \geq 0\right\}$ using the weak infinitesimal operator $L(\varepsilon)$ (Dynkin, 1965), which is defined by the following formula for any sufficiently smooth function $v(x)$ (Dynkin, 1965):

$(L(\varepsilon) v)(x):=\lim _{s \rightarrow+0} \frac{1}{s}\left[\mathbb{E}\left\{v\left(\left.x_{\varepsilon}(t+s)\right|_{x_{\varepsilon}(t)=x}\right\}-v(x)\right]\right.$

By definition for small $s>0$ :

$$
\begin{aligned}
\mathbb{E}\{v(x \varepsilon(t+s)) \mid x \varepsilon(t)=x, s<\tau k-\tau k-1\}-v(x)= \\
\quad=\operatorname{ax}\left(1-K^{-1} x\right) v^{0}(x) s+o(s)
\end{aligned}
$$

and

$$
\begin{aligned}
\mathbb{E}\{v(x \varepsilon(t+s))-v(x) \mid x \varepsilon(t) & =x, s<\tau k-\tau k-1\}= \\
= & \mathbb{E}\left\{v\left(x-\varepsilon \xi_{\kappa} x\right)-v(x)\right\} s+o(s)
\end{aligned}
$$

Combining equations (6) and (7) and considering the formula for jump condition (3) we may rewrite the equation for weak infinitesimal operator in the following form:

$$
\begin{aligned}
& L(\varepsilon) v(x):=\lim _{s \rightarrow+0} \frac{1}{S}\left[\mathbb{E}\left\{\left.v\left(x_{\varepsilon}(t+s)\right)\right|_{x_{\varepsilon}(t)=x}\right\}-v(x)\right]= \\
& \quad=a x\left(1-K^{-1} x\right) v^{\prime}(x)+\frac{1}{\varepsilon} \lambda \mathrm{E}\left(v\left(x-\varepsilon \xi_{k} x\right)-v(x)\right)+O(\varepsilon)= \\
& \quad=\left(a x-K^{-1} x^{2}\right) v^{\prime}(x)-\lambda h x v^{\prime}(x)+ \\
& \quad+\varepsilon \lambda \frac{h^{2}+b^{2}}{2} v^{\prime \prime}(x)+o(\varepsilon)=O(\varepsilon) \\
& \quad=\left[(a-\lambda h)-K^{-1} x\right] x v^{\prime}(x)+O(\varepsilon)
\end{aligned}
$$

As proved in Tsarkov $(1993,2002)$ if the value $|a-\lambda h|$ is sufficiently large, the behaviour of the process $\left\{x_{\varepsilon}(t)\right\}$ on any finite time interval $[0, T]$ may be approximated with the solution of the following ordinary differential equation:

$\frac{d}{d t} \bar{x}(t)=(a-\lambda h) \bar{x}(t)-a K^{-1} \bar{x}(t)^{2}$

to which we will refer as "average equation". This means that for any $x_{\varepsilon}(0) \geq 0$ and $T>0$ there exist such numbers $\varepsilon_{0}>0, M>0$ that for any positive $\varepsilon<\varepsilon_{0}$ we may write the inequality

$\mathbb{E}\left\{\sup _{0 \leq t \leq T}\left|x_{\varepsilon}(t)-\bar{x}(t)\right|\right\}<M \varepsilon$

where $\{\bar{x}(t)\}$ is the solution of equation (9) with initial condition $x(0)=x_{\varepsilon}(0)$. The equation (9) has two stationary solutions: $\bar{x}_{1}=0$ and $x_{2}=K(1-\lambda h / a)$. The Markov dynamical system (3)-(4) also has a trivial solution. If $a<\lambda h$ then one can prove that any solution of the equation (9) with positive 
initial condition tends to the stationary point $x_{1}$. Therefore, as it has been proved in Tsarkov (2002), if $\varepsilon$ is a sufficiently small positive number, any trajectory of the Markov dynamical system (3)-(4) with positive initial condition tends to zero with probability one. If $a>\lambda h$ then stationary point $x_{1}$ is unstable, whereas stationary point $x_{2}$ is exponentially stable. Applying formula (10) we can confirm that for small positive $\varepsilon$ and sufficiently large $t$ the population described by the Markov dynamical system (3)-(4) will be located in $\varepsilon$-neighbourhood of the point $x_{2}=K\left(1-\frac{\lambda h}{a}\right)$. The proximity of the population size to this stationary point may be estimated (Tsarkov, 1993; 2002) to an accuracy within $O(\varepsilon)$ by the normalised deviations:

$y_{\varepsilon}(t):=\frac{x_{\varepsilon}(t)-\bar{x}(t)}{\sqrt{\varepsilon}}$

This process also possesses the Markov properties and for sufficiently smooth function $v(y)$ and infinitesimal $s$ we can approximate:

$$
\begin{aligned}
& {\left[\mathbb{E}\left\{\left.v\left(y_{\varepsilon}(t+s)\right)\right|_{y_{\varepsilon}(t)=y, s<\tau_{k}-\tau_{k-1}}\right\}-v(x)\right]=} \\
& \quad=\left(a y\left(1-2 K^{-1} \bar{x}(t)\right)+\frac{1}{\sqrt{\varepsilon}} \lambda h \bar{x}(t)\right) v^{\prime}(y) s+o(s), \\
& \quad\left[\mathbb{E}\left\{v\left(y_{\varepsilon}(t+s)\right)-\left.v(y)\right|_{y_{\varepsilon}(t)=y, s>\tau_{k}-\tau_{k-1}}\right\}=\right. \\
& \quad=\left[v^{\prime}(y) \mathbb{E}\left(-\varepsilon \xi_{k} y-\sqrt{\varepsilon} \xi_{k}(\bar{x}(t))\right)+\right. \\
& \left.\quad+\frac{1}{2} \varepsilon \mathbb{E}\left(\xi_{k}^{2}\right) v^{\prime \prime}(y)(\bar{x}(t))^{2}\right] s+o(s),
\end{aligned}
$$

Therefore, the weak infinitesimal operator $\bar{L}(\varepsilon)$ of the Markov process $\left\{y_{\varepsilon}(t)\right\}$ may be decomposed to an accuracy within $O(\sqrt{\varepsilon})$ as follows:

$$
\begin{aligned}
\bar{L}(\varepsilon) v(y):= \\
\quad=\lim _{s \rightarrow+0} \frac{1}{s}\left[\mathbb{E}\left\{\left.v\left(y_{\varepsilon}(t+s)\right)\right|_{y_{\varepsilon}(t)=y}\right\}-v(x)\right]= \\
=\left(a y\left(1-2 K^{-1} \bar{x}(t)\right)+\frac{1}{\sqrt{\varepsilon}} \lambda h \bar{x}(t)\right) v^{\prime}(y)+O(\sqrt{\varepsilon})+ \\
\quad+\lim _{s \rightarrow+0} \frac{1}{\varepsilon} \lambda \mathbb{E}\left(v\left(y-\varepsilon \xi_{k} y-\sqrt{\varepsilon} \xi_{k} \bar{x}(t)\right)-v(y)\right)= \\
=\left[(a-\lambda h)-2 K^{-1} \bar{x}(t)\right] y v^{\prime}(y)+ \\
\quad+\frac{1}{2} \lambda\left(h^{2}+b^{2}\right) v^{\prime \prime}(y)(\bar{x}(t))^{2}+O(\sqrt{\varepsilon})
\end{aligned}
$$

This means that the normalised deviations (11) may be approximated by the solution of the stochastic differential equation

$$
\begin{gathered}
d y(t)=\left[(a-\lambda h)-2 K^{-1} \bar{x}(t)\right] y(t) d t+ \\
+\bar{x}(t) \sqrt{\lambda\left(h^{2}+b^{2}\right)} d w(t)
\end{gathered}
$$

with initial condition $y_{\varepsilon}(0)=0$. If the initial population size is equal to $x_{\varepsilon}(0)=x_{2}$ then the equation (13) has more simple form:

$d y(t)=-\left(1-\frac{\lambda h}{a}\right) y(t) d t+$

$$
+K\left(1-\frac{\lambda h}{a}\right) \sqrt{\lambda\left(h^{2}+b^{2}\right)} d w(t)
$$

The difference of any two solutions $\bar{y}(t)=y^{(1)}(t)-y^{(2)}(t)$ satisfies an ordinary differential equation $d \bar{y}(t)=-(1-$ $\left.\frac{\lambda h}{a}\right) \bar{y}(t) d t$ and therefore may presented in the exponential form $\bar{y}(t)=\bar{y}(0) \exp \left\{\left(\frac{h}{a}-1\right) t\right.$. Besides, under condition $a>\lambda h$ we may construct the solution of equation (14) in a form of the Ito stochastic integral:

$$
\begin{aligned}
& \hat{y}(t)=K\left(1-\frac{\lambda h}{a}\right) \sqrt{\lambda\left(h^{2}+b^{2}\right.} \times \\
& \times \int_{-\infty}^{t} \exp \left\{-\left(1-\frac{\lambda h}{a}\right)(t-\tau)\right\} d w(\tau)
\end{aligned}
$$

By definition $\hat{y}(t)$ is a Gaussian random variable with a zero mean and is not dependent on the $t$ variance $\mathrm{D} \hat{y}(t) \equiv$ $K^{2} \lambda(a-\lambda h)\left(h^{2}+b^{2}\right) / 2 a$. Therefore, under condition $a>\lambda h$ the Markov process defined by this stochastic differential equation possesses an ergodic property due to any solution $y(t)$ of equation (13) being presented in a form $y(t)=\hat{y}(t)+$ $\{y(t)-\hat{y}(t)\}$ where the second term exponentially tends to zero but the first term is not dependent on the distribution of $t$. Hence, for a sufficiently small value of $\varepsilon>0$, if the initial population size is within $\varepsilon$ distance from the point $x_{2}=$ $K\left(1-\frac{\lambda h}{a}\right)$ under condition $a>\lambda h$, we may be sure that population does not leave the $\varepsilon$-neighbourhood of the point $x_{2}$ and the population size may be approximated by Gaussian random variable $\varsigma$ with the parameters:

$$
\mathbb{E} \varsigma=K\left(1-\frac{\lambda h}{a}\right), \mathbb{D} \varsigma=\varepsilon \frac{K^{2} \lambda(a-\lambda h)\left(h^{2}+b^{2}\right)}{2 a}
$$

\section{THE DIFFUSION APPROXIMATION}

Here we analyse the behaviour of the population under the assumption that the difference $|a-\lambda h|$ is proportional to the small parameter $\varepsilon$, that is, $a-\lambda h=\varepsilon c, c \neq 0$. Using this assumption, the equation (9) is not applicable because $\lim L(\varepsilon) v(x)=0$ for any $x>0$ and any sufficiently smooth function $v(x)$. Besides, the equilibrium point $x_{2}=K\left(1-\frac{\lambda h}{a}\right)$ is proportional to $\varepsilon$ and we may not rush $\varepsilon$ to 0 . However, for large population size $K$ of order $\varepsilon_{1}$ we have no infinitesimal stationer and the analysis of the dynamical system (2)-(3)-(4) is possible. To assess the behaviour of the random process $\left\{x_{\varepsilon}(t), t>0\right\}$ under the above assumptions we will scale the time and the population size: $X_{\varepsilon}(t):=$ $(\varepsilon K)^{-1} x_{\varepsilon}(t / \varepsilon)$. Taking into account that the switching times $\left\{\tau_{k}^{\varepsilon}, k \in \mathbf{N}\right\}$ for this process are defined by equalities $=\varepsilon \tau_{k}$, $k \in \mathbf{N}$, we can rewrite the equations (2), (3) and (4) for each $k \in \mathbf{N}$ as follows:

$$
\begin{aligned}
& \tau_{k-1}^{\varepsilon} \leq t<\tau_{k}^{\varepsilon}: \frac{d}{d t} X_{\varepsilon}(t)=\frac{1}{\varepsilon}(\lambda h+\varepsilon c) X_{\varepsilon}(t)\left(1-\varepsilon X_{\varepsilon}(t)\right), \\
& P\left(\tau_{k}^{\varepsilon}-\tau_{k-1}^{\varepsilon}>t\right)=e^{-\lambda \varepsilon^{-2} t} \\
& X_{\varepsilon}\left(\tau_{k}^{\varepsilon}\right)=X_{\varepsilon}\left(\tau_{k}^{\varepsilon}-\right)\left(1-\varepsilon \xi_{k}\right)
\end{aligned}
$$

To achieve the diffusion approximation (Tsarkov, 2002) for the Markov process $\left\{X_{\varepsilon}(t)\right\}$ we have to apply the weak infini- 
tesimal operator $L(\varepsilon)$ that is defined by this process to the sufficiently smooth function $v(x)$ :

$$
\begin{aligned}
& L(\varepsilon)[v(X))]:= \\
& \left.=\lim _{s \rightarrow+0} \frac{1}{s}\left[\left.E\left\{v\left(X_{\varepsilon}(t+s)\right)\right)\right|_{X_{\varepsilon}(t)=X}\right\}-V(X)\right]= \\
& =\frac{1}{\varepsilon}(\lambda h+\varepsilon c) X(1-X) v^{\prime}(X)+ \\
& +\frac{1}{\varepsilon^{2}} \lambda \mathbf{E}\left(v\left(X-\varepsilon \xi_{k} X\right)-v(X)\right)= \\
& =\frac{1}{\varepsilon}\left(\lambda h X+\varepsilon c X-(\lambda h+\varepsilon c) X^{2}\right) v^{\prime}(X)- \\
& \left.-\frac{1}{\varepsilon} \lambda h X v^{\prime}(X)+\lambda \frac{h^{2}+b^{2}}{2} X^{2}\right) v^{\prime \prime}(X)+o(\varepsilon)
\end{aligned}
$$

and to pass to a limit as $\varepsilon \rightarrow 0$ :

$\left.\lim _{\varepsilon \rightarrow 0} L(\varepsilon)(X)=X(c-\lambda h X) v^{\prime}(X)+\lambda \frac{h^{2}+b^{2}}{2} X^{2}\right) v^{\prime \prime}(X)$

This means that the diffusion approximation $\{X(t), t \geq 0\}$ for the process $X_{\varepsilon}(t):=(\varepsilon K)^{-1} x_{\varepsilon}(t / \varepsilon)$ has the form of the Ito stochastic differential equation

$d X=X(c-\lambda h X) d t+\sqrt{\lambda\left(h^{2}+b^{2}\right)} X d w(t)$

To minimise the number of parameters in further calculations we will operate with the process $z(t)=\lambda h c^{-1} X(t)$ satisfying the equation

$d z=c z(1-z) d t+\sigma z d w(t)$

where $\sigma=\sqrt{\lambda\left(h^{2}+b^{2}\right)}$. In order to be able to conclude that the population will not disappear for a sufficiently long time we have to analyse the asymptotic stability condition for the trivial solution of the equation (20). Hence, the point is an absorbing boundary for any trajectory satisfying this equation. Therefore, applying the method proposed in Tsarkov (1993) we can use the function $v(z)=z^{\gamma}$ where $\gamma>0$ as a Lyapunov function for a global asymptotic stability analysis of the trivial solution. By applying the Ito formula to the process $v(z(t))$, we can derive the following equation:

$$
\begin{aligned}
& d v(z(t))= \\
& \quad=v^{\prime}(z(t))\{c z(t)(1-z(t)) d t+\sigma(t) z d w(t)\}+ \\
& \quad+\frac{\sigma^{2} z^{2}(t)}{2} v^{\prime \prime}(z(t)) d t= \\
& \quad=\gamma z^{\gamma-1}(t)\{c z(t)(1-z(t)) d t+\sigma z(t) d w(t)\}+ \\
& \quad+\gamma(\gamma-1) \frac{\sigma^{2} z^{2}(t)}{2} z^{\gamma-2}(t) d t= \\
& \quad=\gamma\left[c+(\gamma-1) \frac{\gamma^{2}}{2}\right] v(z(t))(1-z(t)) d t+\gamma \sigma v(z(t)) d w(t)
\end{aligned}
$$

Applying the mathematical expectation procedure to the equation above and taking into account that by definition inf $z(t), \geq 0$, we can write the equation

$$
\begin{aligned}
\frac{d}{d t} & \mathbb{E}\{v(z(t)\}= \\
& =\gamma\left[c+(\gamma-1) \frac{\sigma^{2}}{2}\right] \mathbb{E}\{(1-z(t) v(z(t))\} \leq \\
& \leq \gamma\left[c+(\gamma-1) \frac{\sigma^{2}}{2}\right] \mathbb{E}\{v(z(t))\}
\end{aligned}
$$

and therefore by Gronwall lemma we can derive the inequality

$$
\mathbb{E}\left\{z^{\gamma}(t)\right\}=\leq \mathbb{E}\left\{z^{\gamma}(0) \exp \left\{\gamma\left(c+(\gamma-1) \frac{\sigma^{2}}{2}\right) t\right\}\right.
$$

for any $\gamma>0$. If $2 c<\sigma^{2}=\lambda\left(h^{2}+b^{2}\right)$ we can chose such a positive number $\gamma$ that $c+(\gamma-1) \sigma^{2} / 2$ and then (Tsarkov, 2002) for any initial population size the population will decrease asymptotically.

Now let $2 c>\sigma^{2}=\lambda\left(h^{2}+b^{2}\right)$. Performing the substitution $z(t)=Y^{-1}(t)$ in the equation (20) we can write a linear non-homogeneous stochastic equation for $Y(t)$ :

$d Y(t)=\left(-c+\sigma^{2}\right) Y(t) d t-\sigma Y(t) d w(t)+c d t$

The difference of any two solutions $Y(t)=Y^{(1)}(t)-Y^{(2)}(t)$ of equation (21) satisfies the ordinary stochastic Ito differential equation

$d \bar{Y}(t)=\left(-c+\sigma^{2}\right) \bar{Y}(t) d t-\sigma \bar{Y}(t) d w(t)$

The solution of this equation with initial condition $\bar{Y}(0)=Y$ has a form of the stochastic exponent

$$
\begin{gathered}
\bar{Y}(t)=Y \exp \left\{\left(\frac{\sigma^{2}}{2}-c\right) t-\sigma w(t)\right\}= \\
=Y \exp \left\{\left[\left(\frac{\sigma^{2}}{2}-c\right)-\sigma \frac{w(t)}{t}\right] t\right\}
\end{gathered}
$$

It is well known (Doob, 1953) that

$$
\mathbf{P}\left(\lim _{t \rightarrow \infty} \frac{w(t)}{t}=0\right)=1
$$

Therefore, under the assumption $2 c>\sigma^{2}$ the difference of any two solutions of equation (21) will exponentially tend to zero. Besides, under the assumption above there exists a random process

$\bar{Y}(t)=c \int_{0}^{t} e^{\left\{\left(\frac{\sigma^{2}}{2}-c\right)(t-s)-\sigma[w(t)-w(s)]\right\}} d s$

that satisfies the equation (21). The distribution function for this process

$F_{t}(Y)=\mathbf{P}(\hat{Y}(t) \leq Y)$

does not depend on $t$ because for any $\Delta \geq 0$

$$
\begin{aligned}
& \left.\int_{-\infty}^{t} e^{\left\{\left(\frac{\sigma^{2}}{2}-c\right)(t-s)-\sigma(w(t)-w(s))\right.}\right\} d s= \\
& =\int_{-\infty}^{t+\Delta}\left\{e^{\left\{\left(\frac{\sigma^{2}}{2}-c\right)(t+\Delta-s)-\sigma(w(t+\Delta)-w(s))\right.}\right\} d s= \\
& =\int_{-\infty}^{t} e^{\left\{\left(\frac{\sigma^{2}}{2}-c\right)(t-u)-\sigma(w(t+\Delta)-w(u+\Delta))\right\}} d s
\end{aligned}
$$

and $w(t+\Delta)-w(u+\Delta)$ has the same distribution as $w(t)-$ $w(u)$. Therefore, $F_{t}(Y) \equiv F_{0}(Y)$. Any solution $\tilde{Y}(t)$ of the equation (21) may be presented as a sum $\tilde{Y}(t)\}=\hat{Y}(t)+$ $\tilde{Y}(t)-\hat{Y}(t)$ where the second term satisfies the stochastic Ito ordinary differential equation and therefore has a form of 
stochastic exponent (22). Under the assumption $2 c>\sigma^{2}$ this exponent tends to zero as $t$ tends to infinity. This means that the equation (21) defines the ergodic Markov process (Dynkin, 1965) and

$\lim _{t \rightarrow \infty} \mathbf{P}\left(Y(t) \leq Y / Y(0)=Y_{0}\right)=F_{0}(Y)$

for any initial condition $Y(0)=Y_{0}$. Therefore, if $2 c>\sigma^{2}$, then taking into account the equality $z(t)=Y^{-1}(t)$ we may derive the formula

$$
\begin{aligned}
& \lim _{t \rightarrow \infty} \mathbf{P}\left(z(t) \leq z / z(0)=z_{0}\right)= \\
& \quad=\lim _{t \rightarrow \infty} \mathbf{P}\left(Y(t) \geq z^{-1} / Y(0)=Y\right)= \\
& \quad=1-F_{0}\left(z^{-1}\right):=F(z)
\end{aligned}
$$

Let us denote $p(z)$ as the density function corresponding to $F(z)$. By definition of the stationary distribution of the Markov process defined by the equation (20) (Dynkin, 1965) we can look for the density function $p(x)$ as the positive solution of the second order differential equation

$\frac{d^{2}}{d z^{2}}\left(\frac{\sigma^{2} z^{2}}{2} p(z)\right)-\frac{d}{d z}\{c z(1-z) p(z)\}=0$

satisfying condition $\int_{0}^{\infty} p(z) d z=1$. This solution has an expo-
nential form

$$
p(z)=\frac{\left(\frac{2 c}{\sigma^{2}}\right)^{\frac{2 c-\sigma^{2}}{\sigma^{2}}}}{\Gamma\left(\frac{2 c-\sigma^{2}}{\sigma^{2}}\right)} \int_{0}^{\infty} e^{\left\{-2 c \sigma^{-2} z\right\} z^{2\left(c-\sigma^{-2}\right) \sigma^{-2}}} d z
$$

Note that our analyzed Markov process is defined by formula $X(t)=c(\lambda h)^{-1} z(t)$. Therefore, this process also possesses the ergodic property with the limit distribution

$F_{X}(x)=\lim _{t \rightarrow \infty} \mathbf{P}\left(c(\lambda h)^{-1} z(t) \leq x\right)=F(\lambda h x / c)$

Differentiating this function by $z$ and taking into account the notation $\sigma^{2}=\lambda\left(h^{2}+b^{2}\right)$ we can conclude that under the condition $2 c>\lambda\left(h^{2}+b^{2}\right)$ the population size tends to a random variable that has Gamma-distribution with shape $k=\frac{2 c}{\lambda\left(h^{2}+b^{2}\right)}$ and scale, $\theta=\frac{h^{2}+b^{2}}{2 h}$ i.e., with the density function

$$
p(x)=\frac{\left(\frac{2 h}{h^{2}+b^{2}}\right)^{\frac{2 c}{\lambda\left(h^{2}+b^{2}\right)}-1}}{\Gamma\left(\frac{2 c}{\lambda\left(h^{2}+b^{2}\right)}-1\right)} x^{\frac{2 c}{\lambda\left(h^{2}+b^{2}\right)}-2} e^{-\frac{2 h}{h^{2}+b^{2}}}
$$

Note that we assumed that the difference between the population increase, e.g. birth rate, and extractions, e.g. fishing intensity, is sufficiently small $\varepsilon c$, and that the stationary population size $K$ is of order $\varepsilon^{-1}$ where $\varepsilon$ is small positive parameter. Using this assumption we can make the following conclusion on asymptotic behaviour of the described by the Markov dynamical system (2)-(3)-(4) population growth $x_{\varepsilon}(t)$ : there exists such a positive number $\varepsilon_{0}$, that for any $\varepsilon \in\left(0, \varepsilon_{0}\right)$ and any initial condition $x_{\varepsilon}(0)>0$ :

- if $2 \chi<\lambda\left(h^{2}+b^{2}\right)$ then $\mathbf{P}\left(\lim _{t \rightarrow \infty} x_{\varepsilon}(t)=0\right)=1$;

- if $2 c>\lambda\left(h^{2}+b^{2}\right)$ then $\lim \mathbf{P}\left(\varepsilon^{-1} K x_{\varepsilon}(t) \leq x\right)=F(x)$, where $F(x)$ is the Gamma-distribution with density (31).

\section{REFERENCES}

Anisimov, V. V. (1995). Switching processes: Averaging principle, diffusion approximation and applications. Acta Appl. Math., 40 (2), 95-141.

Doob, J. L. (1953). Stochastic Processes. John Willey \& Sons, New York. $654 \mathrm{pp}$.

Dynkin, E. B. (1965). Markov Processes. Berlin, New Jersey, 1965. 366 pp.

Feldman, M. W., Roughgarden, J. (1975). A population's stationary distribution and chance of extinction in a stochastic environment with remarks on the theory of species packing. Theor. Popul. Biol., 9 (7), 197-207.

Korolyuk, V. S., Limnios, N. (2005). Diffusion approximation of evolutionary systems with equilibrium in asymptotic split phase space. Theor. Probab. Math. Statist., 70, 71-82.

Otto, S. P., Day, T. (1995). A Biologists Guide to Mathematical Modeling in Ecology and Evolution. Princeton University Press, New Jersey.

Prajneshu, P. (1980). Time-dependent solution of the Logistic Model for Population Growth in Random Environment. J. Appl. Prob., 9 (17), 1083-1086.

Tsarkov, Ye. (J. Carkovs) (1993). Averaging in Dynamical Systems with Markov Impulse Perturbations. Bremen University, FRG, 9, Rep. Nr. 282, $41 \mathrm{pp}$.

Tsarkov, Ye. (J. Carkovs) (2002). Asymptotic methods for stability analysis Markov impulse dynamical systems. Nonlinear Dyn. Syst. Theory, 2 (1), $103-115$.

\section{POPULĀCIJAS DINAMIKA, IEVĒROJOT TĀS ĪPATN̦U NEJAUŠUS IMPULSVEIDA ZUDUMUS}

Izmantojot par pamatu Pērla log̣istisko populāciju dinamikas modeli, rakstā veikta populācijas pieauguma kvalitatīva analīze pie nosacījumiem, ka nejaušos laika momentos salīdzinoši neliels populācijas īpatṇu skaits bieži tiek izṇemts no tās dzīvotnes. Šăda populācijas īpatṇu ekstrakcija notiek, piemēram, zivju populācijāa, kur zivju nozvejas rezultātā nejaušos laika momentos no populācijas dzīvotnes tiek izṇemts nejaušs skaits indivīdu, līdz ar to būtiski ietekmējot populācijas dinamiku un tās līdzsvara stabilitāti. Rakstā analizēta populācijas lieluma asimptotika, piedāvāts varbūtību teorijas robežteorēmās balstīts kvalitatīiās analīzes stohastiskās aproksimācijas algoritms patvalīgam galīgam laika intervālam. Analizēts populācijas vidējo lielumu aprakstošs lineārs diferenciālvienādojums un Ito stohastiskais diferenciālvienādojums, kas apraksta normalizētās novirzes no vidējā. Atrasti parametru nosacījumi, pie kuriem populācija konverǵē uz īpatṇu skaitu, kuru apraksta gamma sadalījums ar šajā rakstā aprēkininātiem parametriem, vai pretējā gadījumā — gandrīz droši izmirst. 